\title{
The Rostral Raphe Pallidus Nucleus Mediates Pyrogenic Transmission from the Preoptic Area
}

\author{
Kazuhiro Nakamura, ${ }^{1}$ Kiyoshi Matsumura,, ${ }^{2}$ Takeshi Kaneko,, ${ }^{3,4}$ Shigeo Kobayashi, ${ }^{2}$ Hironori Katoh, ${ }^{1}$ and \\ Manabu Negishi ${ }^{1}$ \\ ${ }^{1}$ Laboratory of Molecular Neurobiology, Graduate School of Biostudies, ${ }^{2}$ Department of Intelligence Science and \\ Technology, Graduate School of Informatics, 'Department of Morphological Brain Science, Graduate School of Medicine, \\ and ${ }^{4}$ Core Research for Evolution Science and Technology, Japan Science and Technology, Kyoto University, Sakyo-ku, \\ Kyoto 606-8502, Japan
}

Fever is the widely known hallmark of disease and is induced by the action of the nervous system. It is generally accepted that prostaglandin $(P G) E_{2}$ is produced in response to immune signals and then acts on the preoptic area (POA), which triggers the stimulation of the sympathetic system, resulting in the production of fever. Actually, the EP3 subtype of PGE receptor, which is essential for the induction of fever, is known to be localized in POA neurons. However, the neural pathway mediating the pyrogenic transmission from the POA to the sympathetic system remains unknown. To identify the neuronal groups involved in the fever-inducing pathway, we first investigated Fos expression in medullary regions of rats after central administrations of $\mathrm{PGE}_{2}$. $\mathrm{PGE}_{2}$ application to the lateral ventricle or directly to the POA strikingly increased the number of Fospositive neurons in the rostral part of the raphe pallidus nucleus
(rRPa). Most of these neurons did not exhibit serotonin immunoreactivity. Microinjection of muscimol, a $\mathrm{GABA}_{\mathrm{A}}$ receptor agonist, into the $\mathrm{rRPa}$ blocked fever and thermogenesis in brown adipose tissue induced by intra-POA as well as by intracerebroventricular $\mathrm{PGE}_{2}$ applications. Furthermore, neural tract tracing studies revealed a direct projection from EP3 receptor-expressing $\mathrm{POA}$ neurons to the $\mathrm{rRPa}$. Our results demonstrate that the $\mathrm{rRPa}$, which has never been associated with the fever mechanism, mediates the pyrogenic neurotransmission from the POA to the peripheral sympathetic effectors contributing to fever development.

Key words: fever; raphe pallidus nucleus; preoptic area; prostaglandin $E_{2}$; EP3 receptor; brown adipose tissue; thermogenesis; autonomic nervous system; GABA; thermoregulation
Fever has been one of the most widely known hallmarks of disease since ancient days (Atkins and Bodel, 1972), and important roles of fever have been indicated in various pathological states (Atkins, 1960; Kluger, 1991). In the generation of the febrile response, prostaglandin ( $\mathrm{PG}) \mathrm{E}_{2}$ is known to play an essential role. It has been proposed that, during infections, $\mathrm{PGE}_{2}$ is produced in brain vasculature in response to immune signals, is released into the brain parenchyma, activates PGE receptors located on neurons, and then triggers the neural circuitry for fever induction (Elmquist et al., 1997; Matsumura et al., 1998; Yamagata et al., 2001). However, the $\mathrm{PGE}_{2}$-triggered neural mechanism for fever induction is still unknown.

The preoptic area (POA) is the major site of action of E-series PGs in the induction of fever (Feldberg and Saxena, 1971; Stitt, 1973; Williams et al., 1977). Our immunohistochemical studies have shown that the EP3 subtype of PGE receptor is somatodendritically localized on neurons in the POA, especially in its

\footnotetext{
Received Nov. 28, 2001; revised Feb. 11, 2002; accepted March 18, 2002.

This work was supported by Grants-in-Aid for Scientific Research and Special Coordination Funds for Promoting Science and Technology from the Ministry of Education, Culture, Sports, Science and Technology of Japan; by Grants-in-Aid for Scientific Research (B) of the Japan Society for the Promotion of Science; and by a grant from the Naito Foundation. K.N. is a Research Fellow of the Japan Society for the Promotion of Science. We are grateful to Takahiro Furuta, Kouichi Nakamura, and Dr. Nobuaki Tamamaki for providing Sindbis virus and anti-EGFP antibody; to Ryohei Tomioka for technical support for in situ hybridization; and to Akira Uesugi for photographic support.

Correspondence should be addressed to Dr. Kazuhiro Nakamura, Department of Morphological Brain Science, Graduate School of Medicine, Kyoto University, Sakyo-ku, Kyoto 606-8501, Japan. E-mail: nkazuhir@pharm.kyoto-u.ac.jp. Copyright (C) 2002 Society for Neuroscience $0270-6474 / 02 / 224600-11 \$ 15.00 / 0$
}

subregions, medial preoptic area (MPO) and median preoptic nucleus (MnPO) (Nakamura et al., 1999, 2000). $\mathrm{PGE}_{2}$ has been thought to exert suppressive effects on functions of the cells expressing EP3 receptor (for review, see Negishi et al., 1995). Among mice lacking each of the known PGE receptor subtypes, only EP3 receptor-deficient mice failed to show a febrile response to $\mathrm{PGE}_{2}$, interleukin-1 $\beta$, or endotoxin (Ushikubi et al., 1998). These observations have led us to hypothesize that the EP3 receptor on POA neurons is the target of $\mathrm{PGE}_{2}$ for its pyrogenic action and that the suppression of POA neuron activity through this receptor activation triggers the neural processes for fever induction.

The action of $\mathrm{PGE}_{2}$ in the POA is thought to trigger the efferent mechanisms that control peripheral sympathetic effectors, including brown adipose tissue (BAT), which is known to be the major organ for thermogenesis during fever in rodents (for review, see Rothwell, 1992). Neural tract tracing and physiological studies have suggested that the sympathetic premotor neurons controlling BAT are distributed in some ventral medullary regions (Bamshad et al., 1999; Uno and Shibata, 2001). For understanding the fever-inducing neural system, it is important to identify the sympathetic premotor regions that receive the pyrogenic $\mathrm{PGE}_{2}$ signal from the POA. In the present study, the neuronal groups excited by central $\mathrm{PGE}_{2}$ administrations were investigated in the ventral medullary regions by immunohistochemically detecting Fos, the protein product of the immediately early gene $c$-fos (Sagar et al., 1988), and $\mathrm{PGE}_{2}$-excited neurons were distributed in the raphe pallidus nucleus ( $\mathrm{RPa})$, especially in 
its rostral part (rRPa). Next, the projection from EP3 receptorexpressing POA neurons to the rRPa was examined with anterograde and retrograde neural tract tracing techniques. Furthermore, the suppression of rRPa neuron activity by microinjecting muscimol, a $\mathrm{GABA}_{\mathrm{A}}$ receptor agonist, was used to examine the role of the $\mathrm{rRPa}$ in the transmission of the pyrogenic signal of $\mathrm{PGE}_{2}$ from the POA to the sympathetic effectors contributing to fever development, including BAT.

\section{MATERIALS AND METHODS}

Animals. One hundred and twelve male Wistar rats (200-250 gm; SLC Japan, Hamamatsu, Japan) were used in the present study. They were housed three or four to a cage with ad libitum access to food and water; the room was kept at $26 \pm 2^{\circ} \mathrm{C}$ with a standard $12 \mathrm{hr}$ light/dark cycle. All experimental procedures were approved by the Animal Care and Use Committee of the Graduate School of Biostudies at Kyoto University.

Intracerebroventricular $P G E_{2}$ stimulation. Rats were deeply anesthetized with sodium pentobarbital $(50 \mathrm{mg} / \mathrm{kg}$, i.p.) and positioned in a stereotaxic apparatus (Narishige, Tokyo, Japan) according to the brain atlas of Paxinos and Watson (1998). A stainless steel cannula (outer diameter, $0.35 \mathrm{~mm}$ ) and a $1 \mathrm{ml}$ disposable syringe were connected with polyethylene tubing, and they were filled with pyrogen-free $0.9 \%$ saline (Otsuka, Tokyo, Japan). The cannula was inserted perpendicularly into the right lateral ventricle (coordinates: $0.8 \mathrm{~mm}$ posterior to the bregma, $1.4 \mathrm{~mm}$ lateral to the midline, and $4.0 \mathrm{~mm}$ ventral to the skull surface). After accuracy of the cannula placement was checked with a flow of the saline into the ventricle by hydrostatic pressure, the polyethylene tubing was cut and its opening end was sealed with heat. The animals were kept for at least 1 week to recover. One day before the experiment, the cannula was flushed with pyrogen-free $0.9 \%$ saline. On the day of the experiment, the rats were anesthetized with urethane $(1.3 \mathrm{gm} / \mathrm{kg}$, i.p.; Sigma, St. Louis, MO) between 10 and 11 A.M. and left on a selfregulating heating pad (KN-474; Natume, Tokyo, Japan) to stabilize the rectal temperature $\left(T_{\text {rec }}\right)$ at $37^{\circ} \mathrm{C}$. The $T_{\text {rec }}$ was monitored with a copperconstantan thermocouple inserted into the rectum through the anus. After $4 \mathrm{hr}, \mathrm{PGE}_{2}(500 \mathrm{ng}$; Sigma) in $15 \mu \mathrm{l}$ of pyrogen-free $0.9 \%$ saline or only saline was injected into the ventricle through the cannula. After $1 \mathrm{hr}$ of $T_{\text {rec }}$ monitoring, the animals were immediately fixed transcardially and expression of Fos protein in the brain was immunohistochemically detected as described below.

Intra-MPO $P G E_{2}$ microinjection. A silica capillary (inner diameter 75 $\mu \mathrm{m}$, outer diameter $150 \mu \mathrm{m}$ ) was connected to Teflon tubing, and they were filled with pyrogen-free $0.9 \%$ saline containing $0.5 \mathrm{mg} / \mathrm{ml} \mathrm{PGE}$ and $0.8 \%$ fluorescent microspheres with a diameter of $0.1 \mu \mathrm{m}$ (F-8801; Molecular Probes, Eugene, OR). A $10 \mu$ l syringe (Hamilton, Reno, NV) filled with mineral oil was connected to the other end of the Teflon tubing. Urethane-anesthetized rats were positioned in a stereotaxic apparatus and left on a self-regulating heating pad to stabilize the $T_{\text {rec }}$ at $37^{\circ} \mathrm{C}$. After $4 \mathrm{hr}$, the capillary was perpendicularly inserted into the MPO (coordinates: $0.0 \mathrm{~mm}$ to the bregma, $0.5-1.0 \mathrm{~mm}$ lateral to the midline, and $8.0-8.5 \mathrm{~mm}$ ventral to the brain surface), and then $100 \mathrm{nl}$ of the $\mathrm{PGE}_{2}$ solution or the vehicle alone was slowly $(10-20 \mathrm{sec})$ injected through the capillary using an infusion pump (Harvard Apparatus, South Natick, MA). The volume of injection was visually confirmed by movement of the aqua-oil interface along the Teflon tubing, which was graduated. After $1 \mathrm{hr}$ of $T_{\text {rec }}$ monitoring, the animals were immediately fixed and subjected to immunohistochemical detection of Fos protein as described below.

Muscimol microinjection. Urethane-anesthetized rats were positioned in a stereotaxic apparatus. To monitor the temperature of the interscapular BAT $\left(T_{\mathrm{BAT}}\right)$, a copper-constantan thermocouple was inserted between the interscapular BAT pad and the underlying connective tissue. The animals were left on a self-regulating heating pad to stabilize the $T_{\text {rec }}$ at $37^{\circ} \mathrm{C}$ in a chamber air-conditioned at $25-27^{\circ} \mathrm{C}$. After $2 \mathrm{hr}$, muscimol (1 mM, $60 \mathrm{nl}$; Sigma), dissolved in pyrogen-free $0.9 \%$ saline containing fluorescent microspheres, or its vehicle alone was microinjected into the ventral medulla as described above in the intra-MPO microinjection. The coordinates for the ventral medulla were $1.3-3.3 \mathrm{~mm}$ posterior to the interaural line, $0.0-2.4 \mathrm{~mm}$ lateral to the midline, and $8.5-9.6 \mathrm{~mm}$ ventral to the brain surface. Ten minutes after the muscimol microinjection, intracerebroventricular injection of $\mathrm{PGE}_{2}$ (500 ng in 15 $\mu l$ pyrogen-free $0.9 \%$ saline) by the method of Cao et al. (1999) or intra-MPO microinjection of $\mathrm{PGE}_{2}(50 \mathrm{ng}$; see above) was performed.
After $2 \mathrm{hr}$ of $T_{\mathrm{BAT}}$ and $T_{\text {rec }}$ recording, the rats were killed by decapitation. Their brains were frozen and coronally sectioned at a thickness of $20 \mu \mathrm{m}$ with a cryostat. After the sections were stained with toluidine blue, the locations of the microinjections were identified by detecting the fluorescent microspheres under an epifluorescence microscope (Eclipse E600; Nikon, Tokyo, Japan) and plotted on drawings from a brain atlas (Paxinos and Watson, 1998).

Sindbis virus and tracer injection. Rats were deeply anesthetized with chloral hydrate $(280 \mathrm{mg} / \mathrm{kg}$, i.p.) and placed in a stereotaxic apparatus. For anterograde tracing studies, we used a replication-deficient recombinant Sindbis virus containing a gene encoding enhanced green fluorescent protein (EGFP) tagged with the $\mathrm{N}$-terminal palmitoylation signal peptide of growth associated protein-43 (palEGFP) (Moriyoshi et al., 1996, Tamamaki et al., 2000) that is driven by a subgenomic promoter of Sindbis virus for expression in mammalian cells (Furuta et al., 2001). The virus solution $\left(0.1-0.5 \mu \mathrm{l}, 2 \times 10^{10}\right.$ infectious unit $\left./ \mathrm{ml}\right)$ was pressureinjected into the POA through a glass micropipette (tip inner diameter $10-15 \mu \mathrm{m}$ ) with the aid of a Picospritzer II (General Valve, Fairfield, $\mathrm{NJ}$ ). The coordinates for the POA were $0.05 \mathrm{~mm}$ posterior to the bregma, $0.7 \mathrm{~mm}$ lateral to the midline, and $8.5 \mathrm{~mm}$ ventral to the brain surface. For retrograde tracing studies, a 4\% solution of Fluoro-Gold (0.1-1.0 $\mu \mathrm{l}$; Fluorochrome, Denver, CO), dissolved in $0.9 \%$ saline, was pressure injected into the ventral medulla $(1.3-3.3 \mathrm{~mm}$ posterior to the interaural line, $0.0 \mathrm{~mm}$ lateral to the midline, and $9.0-9.6 \mathrm{~mm}$ ventral to the brain surface) through a glass micropipette with the aid of a Picospritzer II. Eighteen hours after the virus injection or $3 \mathrm{~d}$ after the Fluoro-Gold injection, each animal was reanesthetized and subjected to the immunohistochemical analyses described below. For tracing studies, expressed palEGFP was visualized by its own fluorescence or by immunohistochemical staining with an anti-EGFP antibody, and Fluoro-Gold was detected by its own fluorescence.

Immunohistochemistry. The immunohistochemical procedures followed our previous studies (Nakamura et al., 2000, 2001). Briefly, the rats treated as described above were fixed by transcardial perfusion with $4 \%$ paraformaldehyde. The brains were postfixed in the fixative, saturated with a sucrose solution, and then cut into 20 - or $40-\mu \mathrm{m}$-thick coronal sections on a cryostat. The sections were consecutively collected into six bottles; six series of sections were obtained from each rat. The sections were incubated overnight with one of the following antibodies: anti-Fos rabbit serum (Ab-5; Oncogene, Cambridge, MA), 1:20,000; anti-rat EP3 receptor rabbit antibody (Nakamura et al., 1999, 2000), $1 \mu \mathrm{g} / \mathrm{ml}$; antiEGFP rabbit antibody (Tamamaki et al., 2000), $0.1 \mu \mathrm{g} / \mathrm{ml}$. After a rinse, the sections were incubated for $1 \mathrm{hr}$ with $10 \mu \mathrm{g} / \mathrm{ml}$ biotinylated donkey antibody to rabbit IgG (Chemicon, Temecula, CA). The sections were rinsed again and reacted for $1 \mathrm{hr}$ with $\mathrm{ABC}$-Elite (1:50; Vector). After a thorough wash of the sections, the bound peroxidase was finally visualized by incubation with $0.02 \%$ 3,3'-diaminobenzidine tetrahydrochloride (DAB) (Dojindo, Kumamoto, Japan) and $0.001 \%$ hydrogen peroxide in $50 \mathrm{~mm}$ Tris-HCl, $\mathrm{pH}$ 7.6.

For double-immunoperoxidase staining of Fos and serotonin, the sections were incubated overnight with the anti-Fos rabbit serum and an anti-serotonin goat serum (1:5000; DiaSorin, Stillwater, MN). After the sections were incubated with biotinylated donkey antibody to goat $\operatorname{IgG}$ (Chemicon) and then with $\mathrm{ABC}$-Elite, the peroxidase was reacted with the DAB solution described above. In this manner, immunoreactivity for serotonin was visualized as a brown reaction product of DAB. The bound peroxidase and unreacted avidin and biotin in the sections were blocked with $3 \%$ hydrogen peroxide and an avidin-biotin blocking kit (Vector), respectively. After a thorough wash, the sections were incubated with biotinylated donkey antibody to rabbit $\operatorname{IgG}$ and then with ABC-Elite. The sections were incubated with $0.02 \% \mathrm{DAB}, 0.0002 \%$ hydrogen peroxide, and $0.5 \%$ ammonium nickel sulfate hexahydrate in 50 mM Tris-HCl, pH 7.6, to visualize Fos immunoreactivity as a blue-black reaction product. By omitting one of the primary antibodies, we confirmed that there was no cross-reactivity between the reagents involved in the two different immunoperoxidase staining steps.

The POA sections from the Sindbis virus- or Fluoro-Gold-injected brains were subjected to immunofluorescence labeling of EP3 receptor as described (Nakamura et al., 2001). After sequential incubations with anti-EP3 receptor rabbit antibody and with biotinylated donkey antibody to rabbit $\mathrm{IgG}$, the sections were incubated with $1 \mu \mathrm{g} / \mathrm{ml}$ Alexa 594conjugated streptavidin (Molecular Probes). The sections were thoroughly washed and mounted onto gelatin-coated glass slides. For doublefluorescence microscopy, an Axiophot epifluorescence microscope (Zeiss, Oberkochen, Germany) was used with an appropriate filter set for 


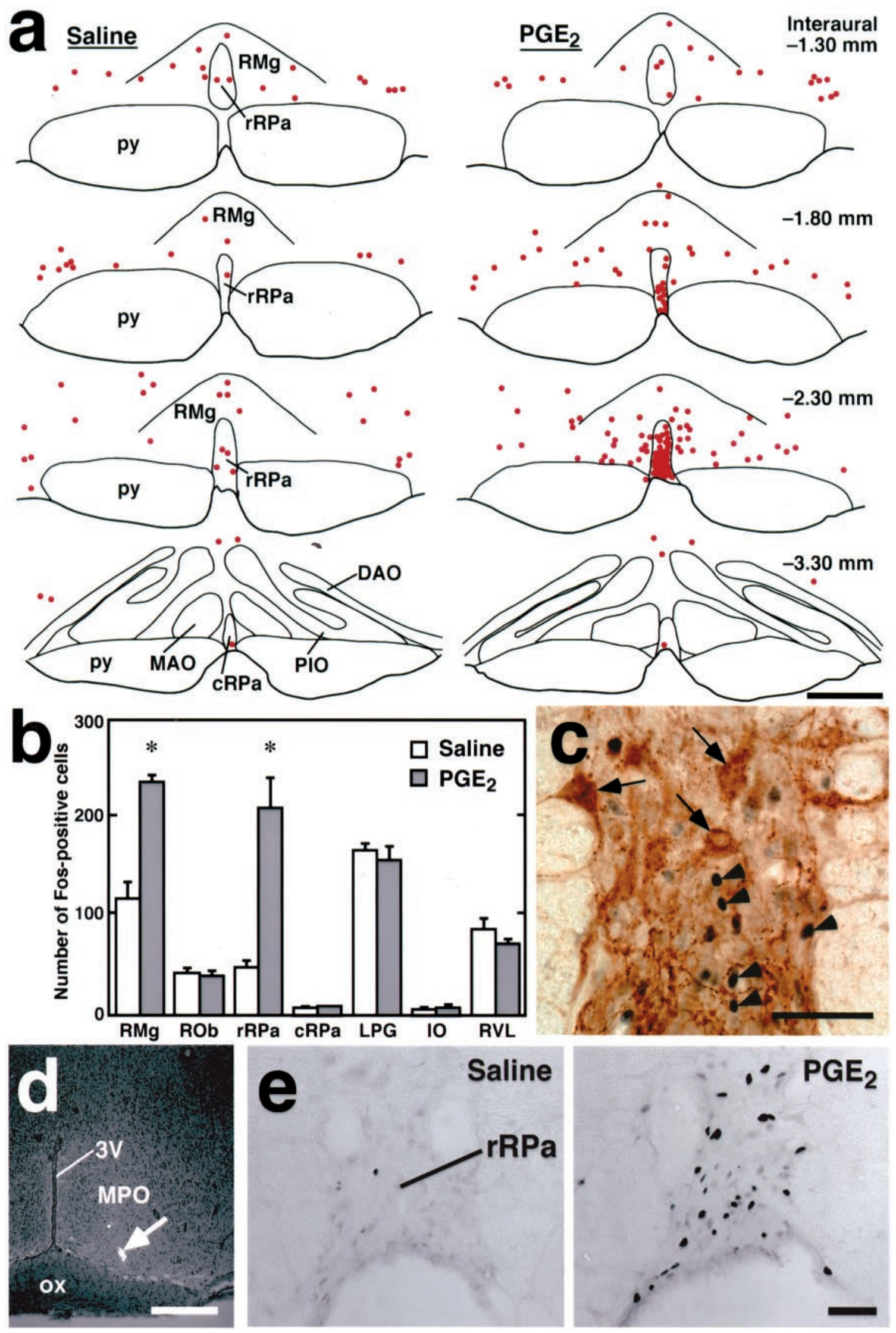

Figure 1. Central $\mathrm{PGE}_{2}$ stimulations induce Fos expression in rRPa neurons. $a$, Distribution of Fos-immunoreactive cells (dots) in the ventral medulla after intracerebroventricular injection of saline or $\mathrm{PGE}_{2}$. Fos-immunoreactive cells in a $20-\mu \mathrm{m}$-thick frontal section of the corresponding rostrocaudal position were plotted on a drawing. Sections set in a row were taken from the same rostrocaudal position, and their (Figure legend continues.) 
Table 1. PGE $_{2}$-induced Fos-expression by nonserotonergic cell groups in the rRPa and RMg

\begin{tabular}{llc} 
& \multicolumn{2}{l}{ Number of Fos-positive cells } \\
\cline { 2 - 3 } Sites & Saline & $\mathrm{PGE}_{2}$ \\
\hline $\mathrm{rRPa}$ & $11.0 \pm 6.1$ & $27.0 \pm 8.5$ \\
$\quad$ Serotonergic & $36.7 \pm 3.7$ & $185 \pm 28^{*}$ \\
$\quad$ Nonserotonergic & & \\
$\mathrm{RMg}$ & $75.7 \pm 11$ & $96.0 \pm 6.0$ \\
$\quad$ Serotonergic & $43.0 \pm 10$ & $142 \pm 14^{*}$ \\
$\quad$ Nonserotonergic & \\
\hline
\end{tabular}

The data represent the mean \pm SEM of three rats per group. $\mathrm{PGE}_{2}$ or saline was injected into the lateral ventricle. Every sixth 20 - $\mu$ m-thick frontal section throughout the medulla oblongata was immunostained (see Fig. 1c) and examined for Fos immunoreactivity in serotonin-immunoreactive cells (Serotonergic) and serotoninimmunonegative cells (Nonserotonergic).

*Significant difference from saline-administered group; $p<0.05$.

Fluoro-Gold (excitation, 360-370 nm; emission, $\geq 395 \mathrm{~nm}$ ), EGFP (excitation, $450-490 \mathrm{~nm}$; emission, $515-565 \mathrm{~nm}$ ), or Alexa 594 (excitation, $530-585 \mathrm{~nm}$; emission, $\geq 615 \mathrm{~nm}$ ).

For the study of cytoarchitecture, one of the rostrocaudal series of the immunolabeled sections was counterstained with cresyl violet. The cytoarchitecture and nomenclature of Paxinos and Watson (1998) were adopted in most regions of the brain, and for the definition of MPO and MnPO we referred to the rat brain atlas by Swanson (1992).

In situ hybridization. Nonradioactive in situ hybridization was performed as described elsewhere (Esclapez et al., 1993). The antisense and sense probes for the $67 \mathrm{kDa}$ form of rat glutamic acid decarboxylase (GAD67) were 619 nucleotides in length. Hybridization using the sense probe did not show any signals. After in situ hybridization, the sections were subjected to immunoperoxidase labeling of EP3 receptor.

Data analysis. All data are presented as the means with the SEM ( \pm SEM). Statistical analysis was performed using the unpaired Student's $t$ test (Instat 2.00 program; Graph Pad, San Diego, CA), and a result was considered significant given a $p$ value of $<0.05$.

\section{RESULTS}

\section{$\mathrm{PGE}_{\mathbf{2}}$-induced Fos expression}

To identify fever-mediating brain regions, we administered $\mathrm{PGE}_{2}$ centrally to trigger fever in rats and examined neuronal activation in the brain by immunohistochemically detecting Fos. In this investigation, we especially focused on the ventral medullary nuclei that had been proposed to contain the sympathetic premotor neurons controlling interscapular BAT (Bamshad et al., 1999; Uno and Shibata, 2001): RPa, raphe magnus nucleus (RMg), raphe obscurus nucleus (ROb), lateral paragigantocellular nucleus (LPG), inferior olivary complex (IO), and rostroventrolateral reticular nucleus (RVL). Intracerebroventricular administration of $\mathrm{PGE}_{2}$ caused a significant rise in $T_{\text {rec }}$ (fever) $\left(2.5 \pm 0.2^{\circ} \mathrm{C}\right.$ in $\mathrm{PGE}_{2}$-injected rats, $n=3 ; 0.13 \pm 0.2^{\circ} \mathrm{C}$ in saline-injected rats, $n=3 ; p<0.005)$ and strikingly increased the density of Fospositive cells in the $\mathrm{RPa}$, especially in its portion rostral to the rostral end of the IO, compared with saline administration (Fig. $1 a$ ). Thus, we nomenclaturally divided the RPa into two parts: rostral and caudal to the rostral end of the IO. These are denoted by rostral part (rRPa) and caudal part (cRPa) of the RPa, respectively. The increase in the density of Fos-positive cells was the most prominent in the caudal one-third of the rRPa (Fig. 1a, Interaural $-2.30 \mathrm{~mm}$ ), but not observed in the $\mathrm{rRPa}$ at the level of the rostral end of the facial nucleus (Fig. 1a, Interaural $-1.30 \mathrm{~mm}$ ) or in the cRPa (Fig. 1a, Interaural $-3.30 \mathrm{~mm}$ ). The dense distribution of the Fos-positive cell group in the rRPa extended into the RMg (Fig. $1 a, P G E_{2}$, Interaural $-2.30 \mathrm{~mm}$ ). These Fospositive cells in $\mathrm{PGE}_{2}$-treated rats were immunoreactive for NeuN, a marker for neurons (data not shown). To verify these observations statistically, we counted the numbers of Fos-positive cells in the ventral medullary regions that might be involved in the sympathetic control of BAT (Bamshad et al., 1999; Uno and Shibata, 2001). $\mathrm{PGE}_{2}$-treated rats exhibited significantly greater numbers of Fos-positive cells in the $\mathrm{rRPa}$ (4.4-fold) and $\mathrm{RMg}$ (2.0-fold) compared with saline-treated controls, whereas Fos expression in the two treatment groups did not differ statistically in the ROb, cRPa, LPG, IO, or RVL (Fig. 1b). These data raised the possibility that the rRPa contains the sympathetic premotor neurons that control BAT functions and consequently fever development.

In addition, the above results raised a question as to whether the Fos-positive neurons in the rRPa and $\mathrm{RMg}$ after the $\mathrm{PGE}_{2}$ administration were serotonergic, because these regions are known to be rich in serotonergic neurons. Thus, we performed double-immunoperoxidase staining for Fos and serotonin. As shown in Figure 1c, most of the rRPa cells with Fos-positive nuclei seen after intracerebroventricular $\mathrm{PGE}_{2}$ injection did not exhibit serotonin immunoreactivity. This observation was assured by a statistical analysis; the $\mathrm{PGE}_{2}$ administration significantly increased the numbers of Fos-positive cells in nonserotonergic cell groups of both $\mathrm{rRPa}$ and $\mathrm{RMg}$ but not in serotonergic cell groups (Table 1).

To examine whether $\mathrm{PGE}_{2}$ triggers the excitation of the rRPa neurons by acting on the POA, we next investigated Fos expression after microinjection of $\mathrm{PGE}_{2}$ directly into the POA. In the POA, EP3 receptor-expressing neurons were reported to be densely localized in the MPO (Nakamura et al., 1999, 2000), and $\mathrm{PGE}_{2}$ microinjection into this subregion was shown to effectively induce fever (Scammell et al., 1996). Thus, to trigger the pyrogenic neural mechanism in the POA, we microinjected $\mathrm{PGE}_{2}$ into the MPO (Fig. 1d). Intra-MPO $\mathrm{PGE}_{2}$ microinjection reliably caused fever $\left(T_{\text {rec }}\right.$ rise; $1.6 \pm 0.4^{\circ} \mathrm{C}$ in $\mathrm{PGE}_{2}$-microinjected rats, $n=3 ; 0.21 \pm 0.1^{\circ} \mathrm{C}$ in saline-microinjected rats, $n=3 ; p<0.005$ ) and induced Fos expression in many $\mathrm{rRPa}$ neurons compared with saline microinjection (Fig. 1e). Most of these Fos-positive neurons were nonserotonergic, and the distribution of these neurons was similar to that seen after the intracerebroventricular injections (data not shown). The results from the Fos-detection studies suggest that a neural system triggered by the $\mathrm{PGE}_{2}$ action

\section{$\leftarrow$}

(Figure legend continued.) distances from the interaural line are indicated based on the brain atlas of Paxinos and Watson (1998). $b$, The numbers of

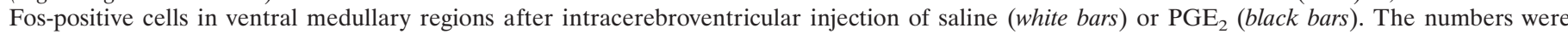
counted in every sixth $20-\mu \mathrm{m}$-thick frontal section throughout the medulla oblongata. Each bar represents the mean \pm SEM of three rats per group. Asterisks indicate statistically significant differences between $\mathrm{PGE}_{2}-$ and saline-injected groups $(p<0.05)$. $c$, Double-immunoperoxidase staining of Fos (blue-black) and serotonin (brown) in the $\mathrm{rRPa}$ (Interaural $-2.30 \mathrm{~mm}$ ) after intracerebroventricular PGE $\mathrm{P}_{2}$ injection. Arrows and arrowheads indicate cells with serotonin and Fos immunoreactivity, respectively. $d$, A representative view of an intra-MPO microinjection site. The injection site was clearly identified as a cluster of fluorescent beads (arrow) in the section counterstained with toluidine blue.e, Fos immunoreactivity in the rRPa (Interaural -2.30 $\mathrm{mm}$ ) after intra-MPO microinjection of saline or $\mathrm{PGE}_{2} .3 \mathrm{~V}$, Third ventricle; $D A O$, dorsal accessory olivary nucleus; $M A O$, medial accessory olivary nucleus; $o x$, optic chiasm; PIO, principal inferior olivary nucleus; $p y$, pyramidal tract. Scale bars: $a, d, 500 \mu \mathrm{m} ; c, 100 \mu \mathrm{m} ; e, 50 \mu \mathrm{m}$. 
in the POA excites the nonserotonergic neurons distributed in and around the rRPa.

\section{Projection from EP3 receptor-expressing POA neurons to the rRPa}

Our observations then prompted us to investigate the neural connections mediating the transmission of $\mathrm{PGE}_{2}$ signal from the POA to the rRPa. To this end, the projection from EP3 receptorexpressing POA neurons to the rRPa was studied using neural tract tracing techniques. Recently, Furuta et al. (2001) have developed a highly sensitive anterograde neural tract tracing technique using a recombinant Sindbis virus that labels the infected neurons in a Golgi stain-like manner. This virus was based on a replication-defective Sindbis virus and designed for the infected cells to express a membrane-targeted fluorescent protein, palEGFP, which is EGFP tagged with a palmitoylation site (Tamamaki et al., 2000). In the first of the present tract tracing studies, we injected the virus into the POA and examined immunoreactivity for palEGFP in the rRPa. In rats injected with the virus unilaterally into the MPO, many cells exhibiting fluorescence of EGFP formed a cluster within the MPO (Fig. 2a), and this cell cluster was located over the EP3 receptor-immunoreactive neuronal group (Fig. $2 b$ ). There were EP3 receptor-immunoreactive neuronal cells infected with the virus (Fig. $2 c, d$, arrow). In these rats, a significant number of EGFP-immunoreactive fibers and boutons were observed in the caudal one-third of the $\mathrm{rRPa}$ (Fig. 2e) and also in the RMg ipsilateral to the site of the virus injection (data not shown). However, EGFP immunoreactivity was not evident in more caudal regions, including the ROb, cRPa, and IO. These observations were obtained from three rats in which we successfully injected the virus into the MPO. Similar projections were also observed when we used a conventional anterograde tracer, Phaseolus vulgaris leucoagglutinin (data not shown).

We further analyzed the presence of EP3 receptor on the POA neurons projecting to the ventral medullary regions by using Fluoro-Gold, a retrograde neural tract tracer. Injection of the tracer into the caudal one-third of the rRPa and surrounding $\mathrm{RMg}$ (Fig. 3a) resulted in double labeling with Fluoro-Gold fluorescence and EP3 receptor immunoreactivity in POA neurons (Fig. 3b, arrows). These double-labeled cells were concentrated in the MPO rather than in the MnPO (Fig. 3c). EP3 receptor immunoreactivity was found in $43.0 \%$ of Fluoro-Goldlabeled cells in the MPO, but in only $6.5 \%$ in the MnPO (counted within the EP3 receptor-immunoreactive region in every sixth 20 - $\mu$ m-thick frontal section). EP3 receptor immunoreactivity was distributed also in the dorsal part of the MnPO (dorsal to the anterior commissure) and in the parastrial nucleus (Nakamura et al., 2000), but we scarcely found Fluoro-Gold-labeled cells in these regions. We successfully performed similar injections into three rats with the tracer and found no significant differences in the observations between the animals. Using the same procedure, we found that Fluoro-Gold injections centered on the rostral one-third of the rRPa or on the cRPa showed no double-labeled cells in the POA (data not shown). Similar results were also obtained using another retrograde tracer, wheat germ agglutinin (data not shown). The neural tract tracing studies demonstrate that a population of EP3 receptor-expressing POA neurons project directly to the caudal portion of the $\mathrm{rRPa}$ and its surrounding $\mathrm{RMg}$.

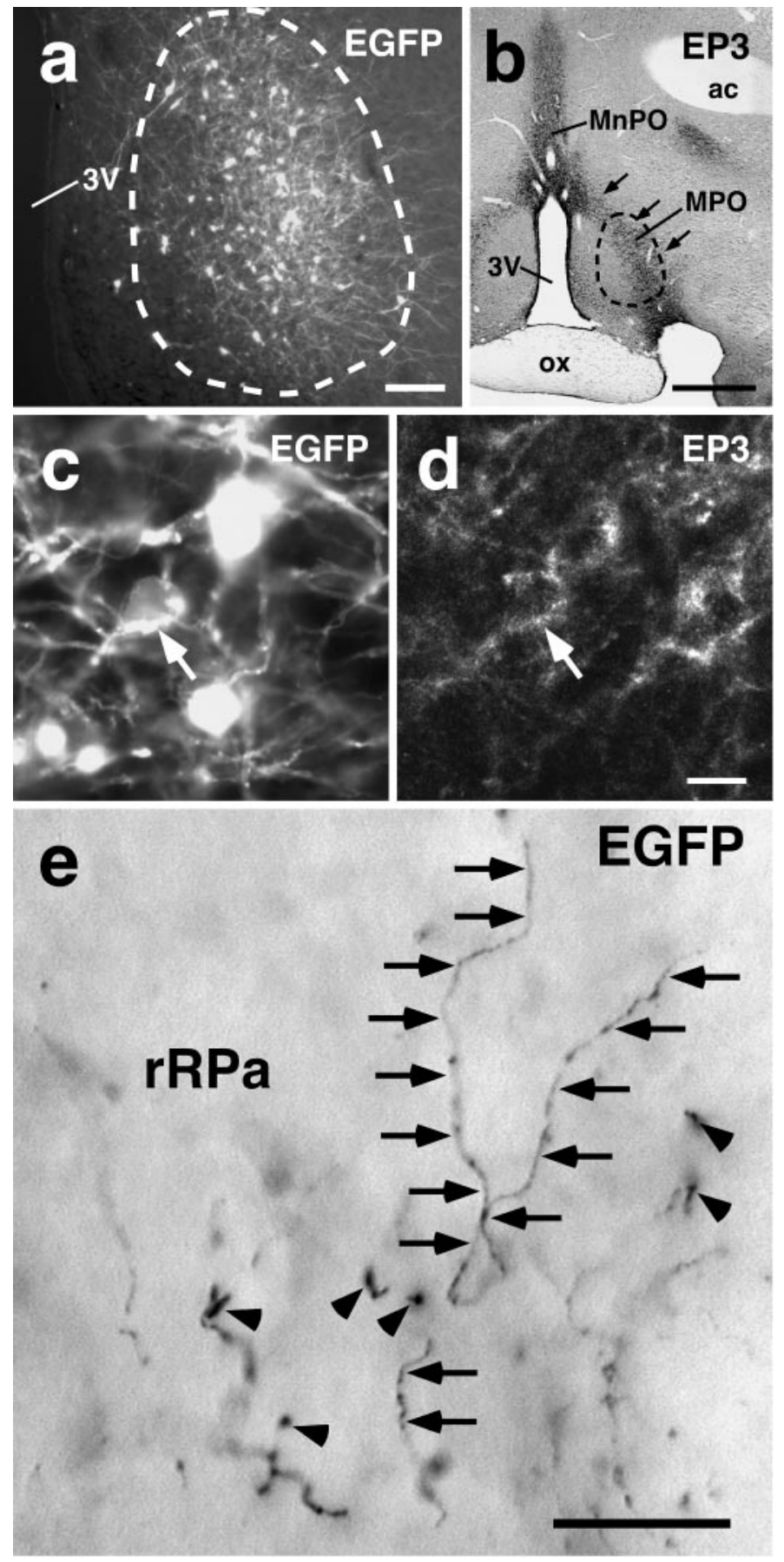

Figure 2. Projections from POA neurons to the rRPa. $a$, Sindbis virus injection into the POA. Infected cells exhibited EGFP fluorescence and formed a cluster (enclosed with a broken line), and many neuronal fibers with fluorescence extended from the cell cluster. $b$, The location of the Sindbis virus injection. A section adjacent to the one shown in $a$ was immunostained for EP3 receptor. The location of the cluster of the infected cells is indicated by a broken line. The cell cluster was located over the EP3 receptor-immunoreactive neuronal cell group in the MPO (arrows). $c, d$, Infection of EP3 receptor-expressing POA neurons with the Sindbis virus. There were POA neuronal cell bodies double labeled with EGFP fluorescence $(c)$ and EP3 receptor immunoreactivity $(d)$ (arrow). The photomicrographs were taken at the same site under different conditions of excitation. $e$, EGFP immunoreactivity in the caudal one-third of the rRPa. The immunoreactivity was localized in fibers (arrows) and boutons (arrowheads). $a c$, Anterior commissure. Scale bars: $a, 100 \mu \mathrm{m} ; b$, $500 \mu \mathrm{m} ; c, d, 10 \mu \mathrm{m} ; \mathrm{e}, 20 \mu \mathrm{m}$. 

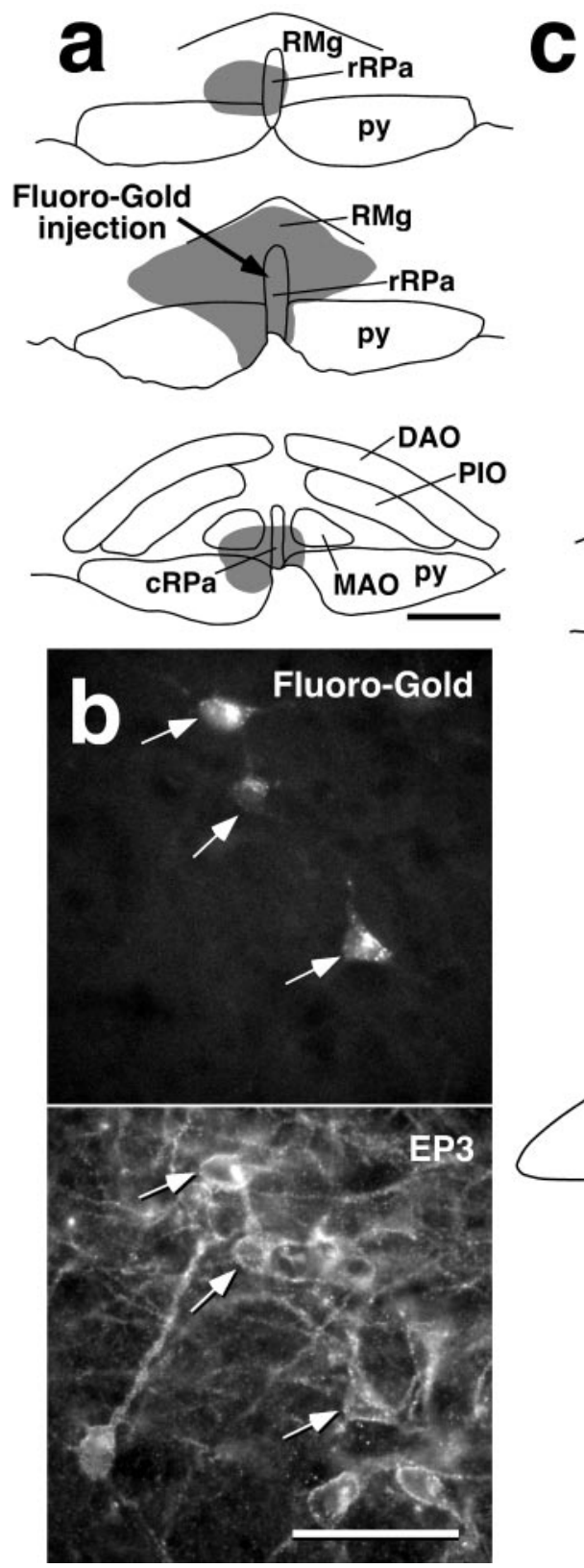

\section{$\bigcirc$ Fluoro-Gold Fluoro-Gold \& EP3}
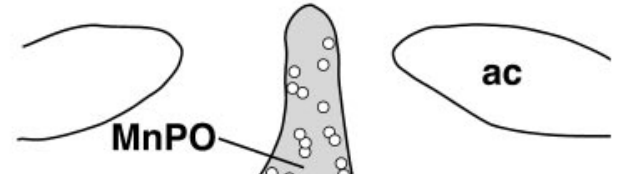
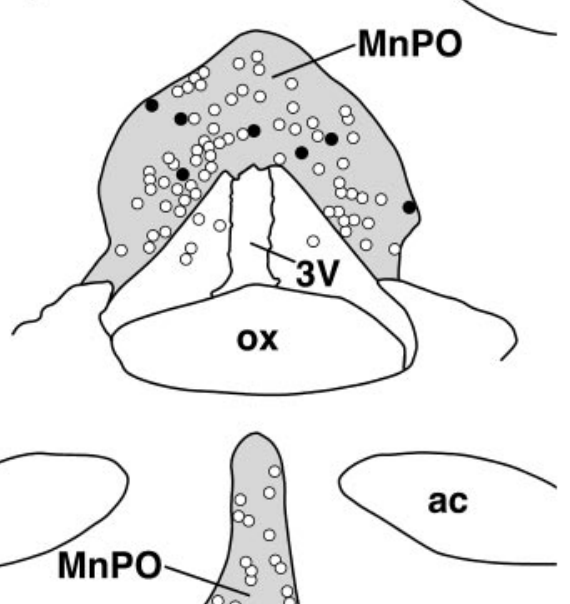

.
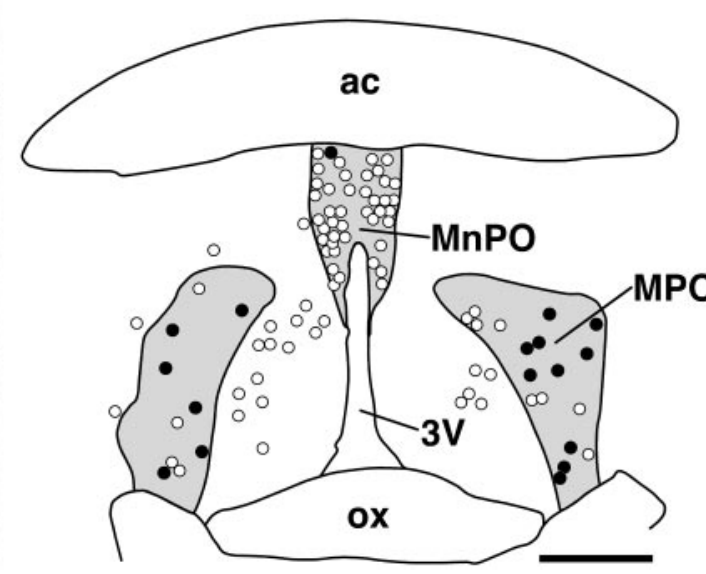

Figure 3. EP3 receptor-expressing POA neurons directly project to the rRPa. $a$, FluoroGold injection centered on the caudal onethird of the rRPa (arrow). $b$, POA neuronal cell bodies double labeled with Fluoro-Gold fluorescence and EP3 receptor immunoreactivity (arrows). The photomicrographs were taken at the same site under different conditions of excitation. $c$, Distributions of POA neurons labeled with Fluoro-Gold (open circles) and with both Fluoro-Gold and EP3 receptor immunoreactivity (filled circles). All Fluoro-Goldlabeled cells distributed in the shown regions were drawn. The distribution area of EP3 receptor-immunoreactive cells is colored gray. Scale bars: $a, c, 500 \mu \mathrm{m} ; b, 50 \mu \mathrm{m}$.

\section{Muscimol microinjection into the rRPa blocks $\mathrm{PGE}_{2}$-induced fever and BAT thermogenesis}

Our present results suggest that $\mathrm{PGE}_{2}$ excites rRPa neurons probably by acting on the EP3 receptor on POA neurons, which hypothetically will lead to the activation of sympathetic pathways projecting to the effectors contributing to fever development, including BAT. We tested this functional relationship by examining the effects of continuous inhibition of $\mathrm{rRPa}$ neurons on fever and BAT thermogenesis evoked by intracerebroventricular or intra-MPO $\mathrm{PGE}_{2}$ stimulation.

Intracerebroventricular $\mathrm{PGE}_{2}$ injection induced a rise in $T_{\mathrm{BAT}}$ of $>2.0^{\circ} \mathrm{C}$, peaking at $20-25 \mathrm{~min}$ after the injection. $T_{\text {rec }}$, the core temperature, started to increase 1-2 min after the $T_{\mathrm{BAT}}$ rise, and its peak was lower than that of $T_{\mathrm{BAT}}$. The characteristics of these temperature changes are consistent with the fact that heat is produced in effectors including BAT during fever and then transferred to the rest of the body. To continuously suppress neuronal activity, we microinjected muscimol into the caudal one-third of the rRPa (Fig. $4 c, d$, Interaural $-2.30 \mathrm{~mm}$ ). The muscimol pretreatment manifestly blocked the rise in both $T_{\mathrm{BAT}}$ and $T_{\text {rec }}$ induced by intracerebroventricular $\mathrm{PGE}_{2}$ administration (Fig. $4 a, b)$. No $T_{\mathrm{BAT}}$ increase of $>0.5^{\circ} \mathrm{C}$ was observed in the rats microinjected with muscimol into the caudal one-third of the rRPa. In contrast, rats microinjected with saline into the caudal one-third of the rRPa (Fig. 4d, open circles) showed $\mathrm{PGE}_{2}-$ induced $T_{\mathrm{BAT}}$ and $T_{\mathrm{rec}}$ rises to the level observed in untreated rats (Fig. $4 a, b)$.

To map the sites at which muscimol microinjection inhibited the $\mathrm{PGE}_{2}$-stimulated BAT thermogenesis, we microinjected muscimol into various regions of the ventral medulla, examined the $T_{\mathrm{BAT}}$ rises induced by intracerebroventricular $\mathrm{PGE}_{2}$ injections, and graded the $T_{\mathrm{BAT}}$ rises as follows: $\leq 0.5^{\circ} \mathrm{C}$, full inhibition; $0.5-2.0^{\circ} \mathrm{C}$, partial inhibition; $\geq 2.0^{\circ} \mathrm{C}$, no inhibition. As shown in Figure $4 d$, full inhibition ( filled circles) was observed only after 

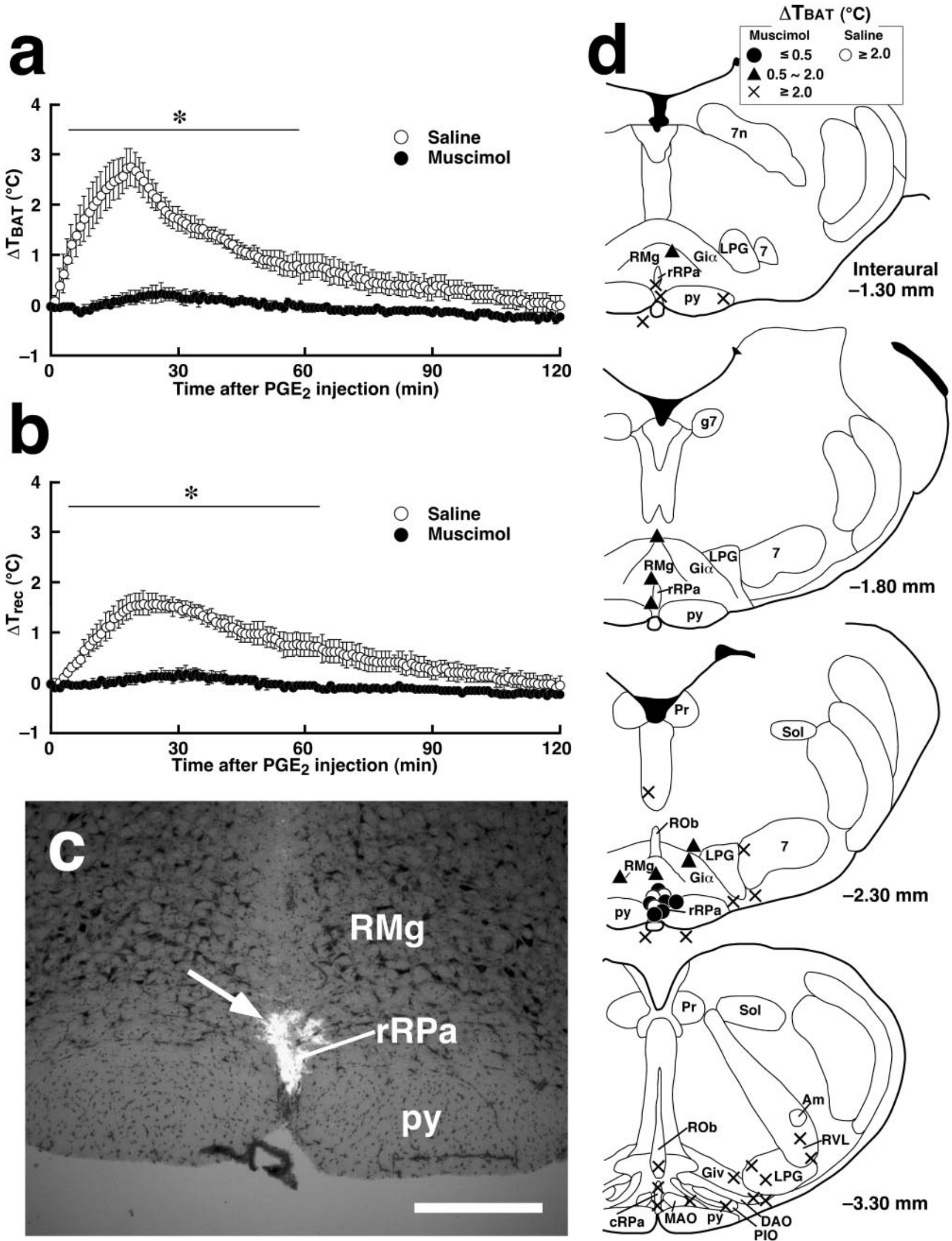

Figure 4. Muscimol microinjection into the rRPa blocks fever and BAT thermogenesis stimulated by intracerebroventricular administration of PGE 2 . $a, b$, Changes in $T_{\mathrm{BAT}}(a)$ and $T_{\text {rec }}(b)$ after intracerebroventricular $\mathrm{PGE}_{2}$ injection in rats microinjected with muscimol or saline into the caudal one-third of the rRPa. The sites of muscimol and saline microinjections are shown in $d$ (Interaural $-2.30 \mathrm{~mm}$ ). Each value represents the mean \pm SEM of three rats per group. The changes in $T_{\mathrm{BAT}}$ and $T_{\mathrm{rec}}$ were significantly different between muscimol- and saline-pretreated (Figure legend continues.) 

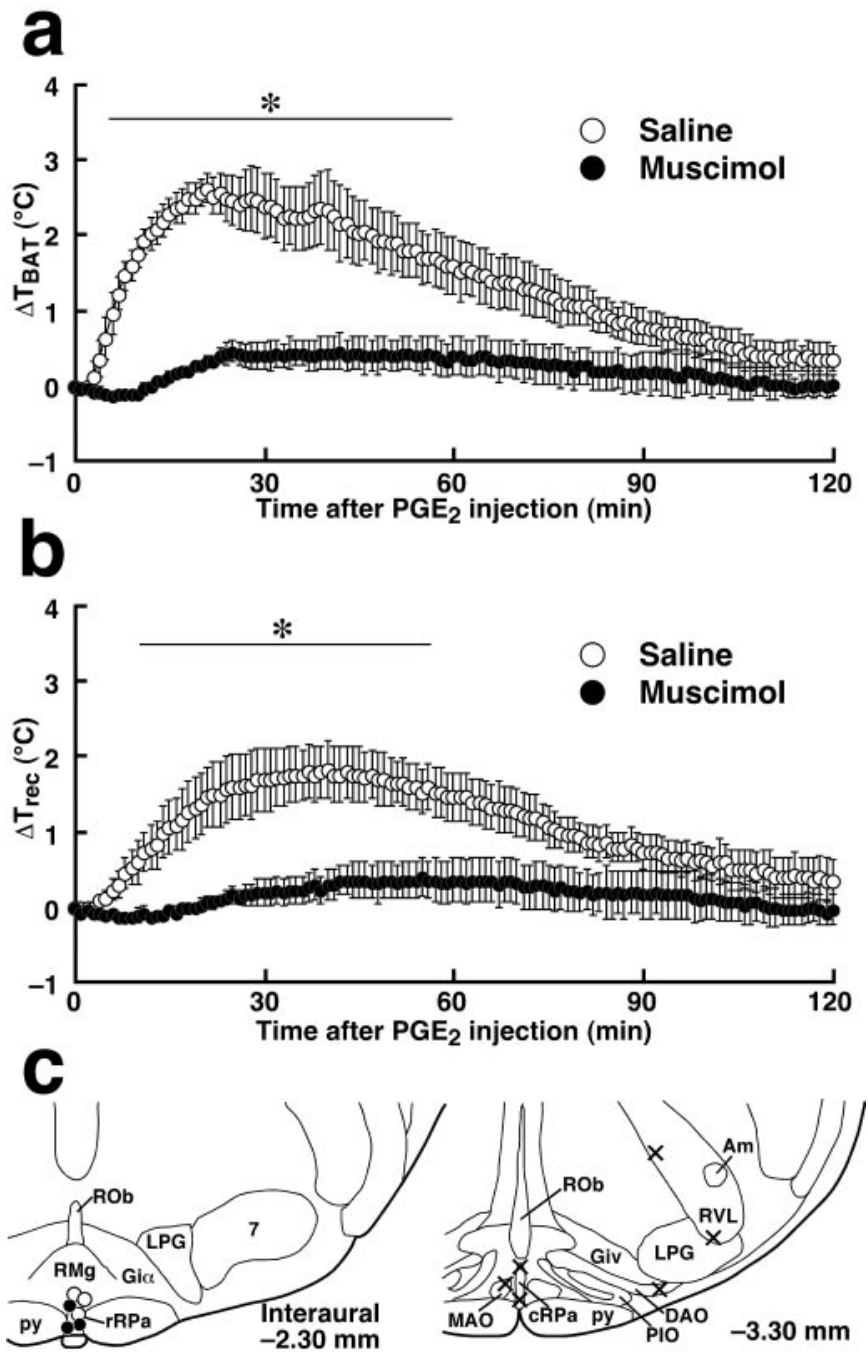

Figure 5. Fever and BAT thermogenesis induced by intra-MPO microinjection of $\mathrm{PGE}_{2}$ are blocked by muscimol microinjection into the $\mathrm{rRPa}$. $a, b$, Changes in $T_{\mathrm{BAT}}(a)$ and $T_{\mathrm{rec}}(b)$ after intra-MPO $\mathrm{PGE}_{2}$ microinjection in rats microinjected with muscimol or saline into the caudal one-third of the rRPa. The sites of muscimol and saline microinjections are shown in $c$ (Interaural $-2.30 \mathrm{~mm}$ ). Each value represents the mean \pm SEM of three rats per group. The changes in $T_{\mathrm{BAT}}$ and $T_{\mathrm{rec}}$ were significantly different between muscimol- and saline-pretreated groups at least during the time period denoted by bars with asterisks $(p<0.05)$. The data shown in $a$ and $b$ are from the same animals. $c$, Composite drawing of the effect of muscimol or saline microinjections into ventral medullary regions on BAT thermogenesis stimulated by intra-MPO $\mathrm{PGE}_{2}$ microinjection. Each symbol represents the site of muscimol microinjection ( filled circles and crosses) or of saline microinjection (open circles) and corresponding change in $T_{\mathrm{BAT}} 40 \mathrm{~min}$ after $\mathrm{PGE}_{2}$ microinjection: $\leq 0.7^{\circ} \mathrm{C}$ ( filled circles); $\geq 2.0^{\circ} \mathrm{C}$ (crosses and open circles). muscimol was microinjected into the caudal one-third of the rRPa. Muscimol microinjections into the regions neighboring the most effective site, such as the middle one-third of the rRPa, the caudal portions of the RMg, and the alpha part of the gigantocellular reticular nucleus, only partially inhibited the BAT thermogenesis (triangles). No inhibition (crosses) was observed when muscimol microinjections were made into the facial nucleus, $\mathrm{ROb}$ or the rostral one-third of the rRPa, cRPa, IO, LPG, or RVL.

We further examined the blocking effect of the continuous inhibition of $\mathrm{rRPa}$ neurons on fever and BAT thermogenesis caused by direct $\mathrm{PGE}_{2}$ application into the MPO. PGE $\mathrm{PG}_{2}$ microinjection into the MPO of untreated rats increased $T_{\mathrm{BAT}}$ by $2.0-3.0^{\circ} \mathrm{C}$ and $T_{\text {rec }}$ by $1.5-2.0^{\circ} \mathrm{C}$. Muscimol microinjection into the caudal one-third of the rRPa (Fig. $5 c$, Interaural $-2.30 \mathrm{~mm}$ ) strongly inhibited the $T_{\mathrm{BAT}}$ and $T_{\text {rec }}$ rises induced by intra-MPO $\mathrm{PGE}_{2}$ microinjection (Fig. $5 a, b$ ); no $T_{\mathrm{BAT}}$ increase of $>0.7^{\circ} \mathrm{C}$ was observed. In rats microinjected with muscimol into the $\mathrm{cRPa}, \mathrm{IO}$, or RVL (Fig. $5 c$, Interaural $-3.30 \mathrm{~mm}$ ) or with saline into the caudal one-third of the rRPa (Figs. $5 a-c$, Interaural $-2.30 \mathrm{~mm}$ ), intra-MPO $\mathrm{PGE}_{2}$ microinjection induced $T_{\mathrm{BAT}}$ and $T_{\text {rec }}$ rises to the level observed in untreated rats. These results suggest that the rRPa mediates the transmission of $\mathrm{PGE}_{2}$ signal from the POA to fever-producing sympathetic effectors.

\section{Expression of a marker for GABAergic neurons in EP3 receptor-expressing POA neurons}

It has been documented that the EP3 receptor acts as a suppressive receptor by coupling with inhibitory GTP-binding proteins (Negishi et al., 1995). Therefore, our results appeared to mean that $\mathrm{PGE}_{2}$-induced suppression of EP3 receptor-expressing POA neurons leads to the excitation of the rRPa neurons. This raised the possibility of tonic inhibition of the rRPa neurons by EP3 receptor-expressing $\mathrm{POA}$ neurons under $\mathrm{PGE}_{2}$-free conditions. In addition, we showed that GABA receptor-mediated inhibition of $\mathrm{rRPa}$ neurons blocked the transmission of pyrogenic $\mathrm{PGE}_{2}$ signal from the POA. Taken together, these lines of knowledge led us to hypothesize that EP3 receptor-expressing POA neurons are GABAergic and directly regulate the activity of the $\mathrm{rRPa}$ neurons. To test this hypothesis, we examined the expression of mRNA for GAD67, a marker for GABAergic neurons, in EP3 receptor-expressing POA neurons. By a combination of immunoperoxidase staining for EP3 receptor and in situ hybridization for GAD67, we found that $86.3 \%$ of EP3 receptor-immunoreactive POA neurons exhibited signals for GAD67 mRNA (Fig. 6a, arrows). This observation indicates that a large population of EP3 receptor-expressing POA neurons are GABAergic, supporting our hypothesis.

\section{DISCUSSION}

The present study demonstrates, for the first time, that the rRPa is essential for fever induction following central $\mathrm{PGE}_{2}$ action. Muscimol microinjection into the caudal one-third of the rRPa

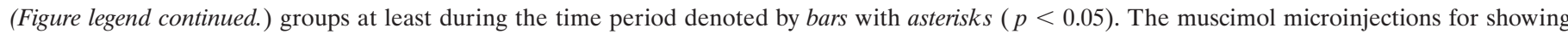

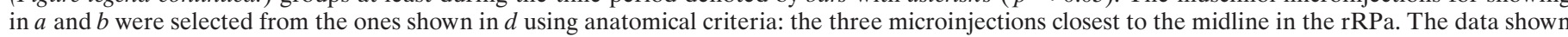

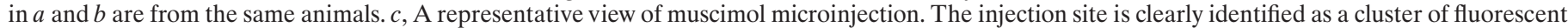

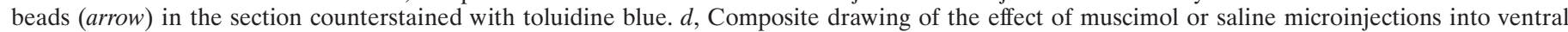

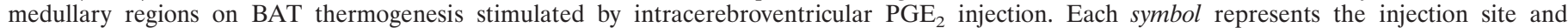

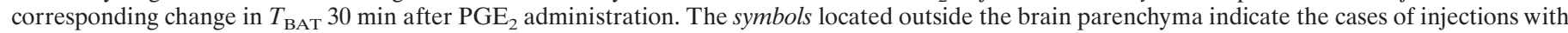

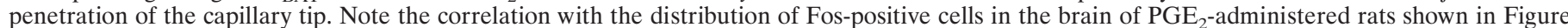

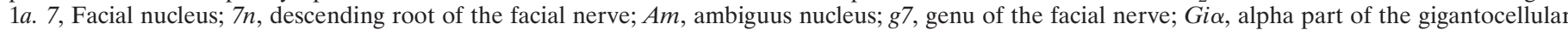

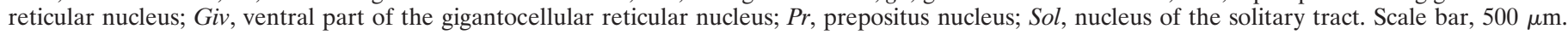



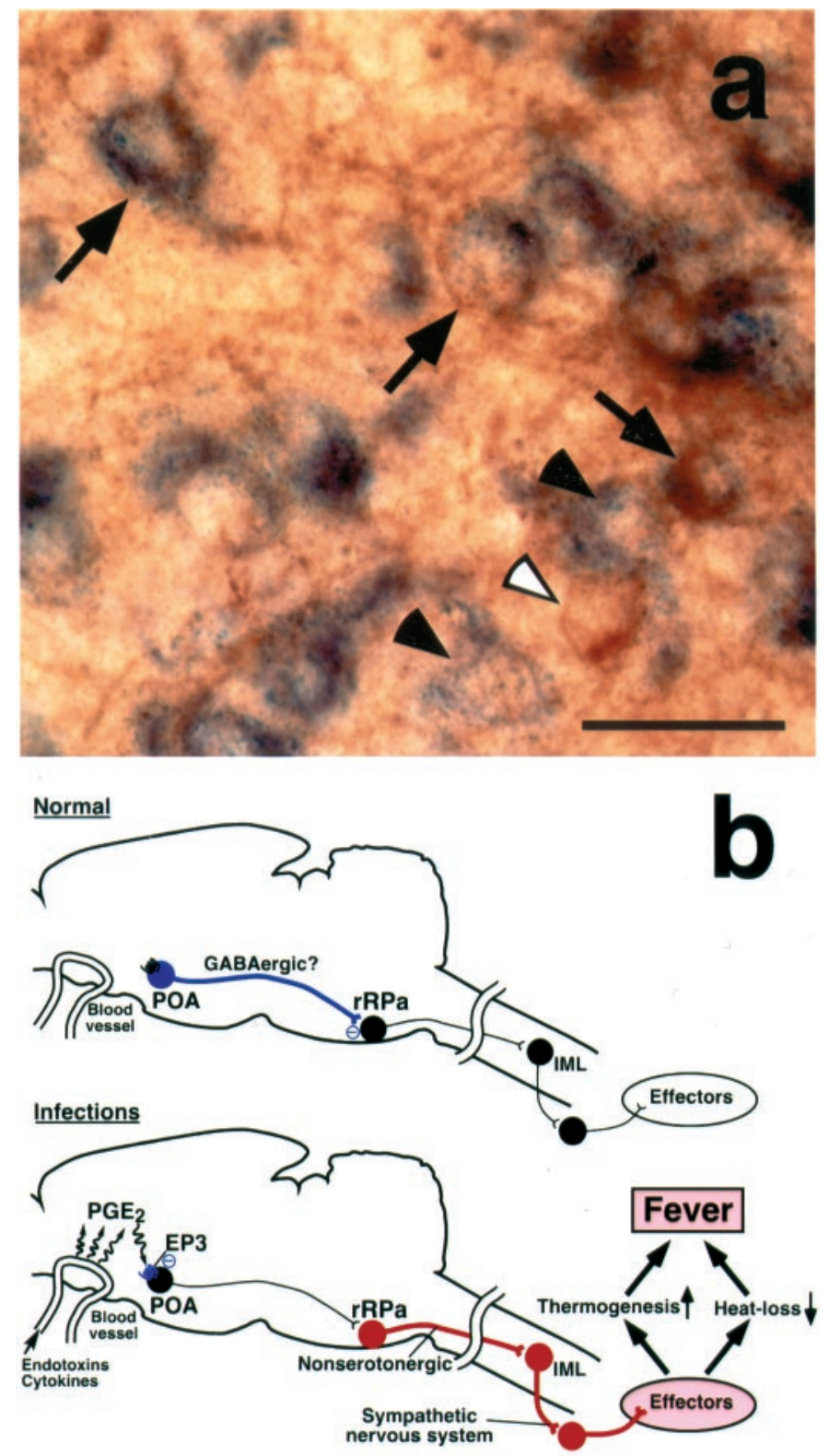

Figure 6. A population of EP3 receptor-expressing POA neurons are GABAergic. $a$, Double labeling with EP3 receptor immunoreactivity (brown) and GAD67 mRNA hybridization (blue) in the POA. Arrows indicate EP3 receptor immunoreactive neurons exhibiting signals for GAD67 mRNA. Filled and open arrowheads indicate neurons single labeled with GAD67 mRNA hybridization and EP3 receptor immunoreactivity, respectively. $b$, Our current hypothesis on the neural pathway mediating $\mathrm{PGE}_{2}$-induced fever. See Discussion for details. Blue, red, and black circles denote cell bodies of activated inhibitory neurons, activated excitatory neurons, and suppressed neurons, respectively. IML, Intermediolateral cell column. Scale bar, $30 \mu \mathrm{m}$.

blocked fever and BAT thermogenesis caused by central $\mathrm{PGE}_{2}$ administrations. Furthermore, the $\mathrm{PGE}_{2}$ action prominently increased Fos expression in a similar region of the rRPa. This $\mathrm{PGE}_{2}$-induced increase in the number of Fos-positive neurons within ventral medullary regions appeared to have a good correlation with the blocking effect of the muscimol that was microinjected into the regions. Thus, the $\mathrm{GABA}_{\mathrm{A}}$ receptor agonist blocked the pyrogenic action of $\mathrm{PGE}_{2}$, probably by suppressing the $\mathrm{PGE}_{2}$-triggered excitation of the rRPa neurons. In addition, it was reported that microinjection of bicuculline, a $\mathrm{GABA}_{\mathrm{A}}$ receptor antagonist, into the $\mathrm{rRPa}$ caused a rise in the sympathetic nerve activity to interscapular BAT (Morrison et al., 1999). Taken together, it is likely that the $\mathrm{rRPa}$ neurons are tonically inhibited by GABAergic inputs, and release of these neurons from the tonic inhibition by a $\mathrm{PGE}_{2}$-triggered mechanism leads to the stimulation of the sympathetic system for fever development.

To trigger this fever-inducing mechanism, $\mathrm{PGE}_{2}$ appears to act on the POA, because the POA is almost the sole brain region in which microinjections of $\mathrm{PGE}_{1}$, a $\mathrm{PGE}_{2}$ analog, effectively evoked fever (Williams et al., 1977). In the POA, especially in the MPO and MnPO, the EP3 subtype of PGE receptor was shown to be localized somatodendritically on neurons (Nakamura et al., 1999, 2000). In addition, EP3 receptor-deficient mice failed to show a febrile response to $\mathrm{PGE}_{2}$ (Ushikubi et al., 1998). Therefore, the transmission of $\mathrm{PGE}_{2}$ signal from the EP3 receptor-expressing POA neurons is likely to be essential for fever induction.

How is the $\mathrm{PGE}_{2}$-evoked pyrogenic signal in the POA transmitted to the rRPa neurons? Although abundant connections between the POA and ventral medullary regions have been reported (Murphy et al., 1999), the functional significance of these connections remains poorly understood. The present muscimol microinjection experiments indicate that descending transmission from the POA to the $\mathrm{rRPa}$ is responsible for the $\mathrm{PGE}_{2}$-triggered stimulation of the fever-producing sympathetic system. Our neural tract tracing studies further revealed the direct projection from EP3 receptor-expressing POA neurons to the caudal portion of the rRPa, suggesting a candidate component of the pyrogenic descending pathway. In addition, the present double labeling for EP3 receptor and GAD67 mRNA showed that a major population of EP3 receptor-expressing POA neurons are GABAergic. On the basis of these results, we propose a possible mechanism of the pyrogenic transmission (Fig. $6 b$ ). Under $\mathrm{PGE}_{2}$-free conditions, rRPa neurons are tonically inhibited by inputs from EP3 receptor-expressing POA neurons, which may be GABAergic (Fig. 6b, Normal ); $\mathrm{PGE}_{2}$, which is produced in brain vasculature during infections (Elmquist et al., 1997; Matsumura et al., 1998; Yamagata et al., 2001), suppresses the tonic firing of the POA neurons by activating the EP3 receptor, disinhibits the $\mathrm{rRPa}$ neurons, stimulates the sympathetic nervous system, and finally develops fever (Fig. 6b, Infections).

In addition to the pyrogenic pathway that we propose here, there may be other brain regions involved in fever induction. The paraventricular hypothalamic nucleus $(\mathrm{PVH})$ has been known as a major site of autonomic control. It was reported that lesions of the PVH reduced febrile responses to intracerebroventricular injection of $\mathrm{PGE}_{2}$ or intraperitoneal administration of endotoxin, although the lesions reduced the febrile responses only partly and did not reduced fever induced by a high dose (50 ng) of $\mathrm{PGE}_{2}$ (Horn et al., 1994). Thus, the PVH might mediate in part the pyrogenic transmission from the POA to the rRPa. Alternatively, the PVH might play an accessory role in the control of the $\mathrm{rRPa}$ neurons independently of the descending pathway from the POA. Another brain region, the ventromedial hypothalamic nucleus (VMH), has been associated with the sympathetic control of BAT (Perkins et al., 1981; Imai-Matsumura et al., 1984; Niijima et al., 1984) and has been proposed to mediate $\mathrm{PGE}_{2}$-stimulated BAT thermogenesis (Amir and Schiavetto, 1990). However, a transneuronal viral tract tracing study reported that there were little or no neural connections between the VMH and interscapular BAT (Bamshad et al., 1999). Furthermore, we found that the present Sindbis virus injections into the POA did not show 
significant EGFP-immunoreactive fibers or boutons in the VMH (K. Nakamura, T. Kaneko, and M. Negishi, unpublished observation). Therefore, it is unlikely that the $\mathrm{VMH}$ plays a significant role in the pyrogenic transmission pathway from the POA.

$\mathrm{RPa}$ neurons project to the intermediolateral cell column (IML) of the spinal cord (Loewy, 1981), which gives rise to outputs to control various sympathetic effectors. Our Fosdetection studies suggest that the rRPa neurons mediating the pyrogenic transmission are nonserotonergic, and previous studies have shown that there is a nonserotonergic population of spinally projecting neurons in the medullary raphe nuclei (Bowker et al., 1981; Skagerberg and Björklund, 1985). Thus, it is plausible that these nonserotonergic $\mathrm{rRPa}$ neurons directly project to the IML and regulate the sympathetic output to thermogenic effectors, including BAT (Fig. 6b).

Furthermore, the rRPa neurons receiving the descending transmission from the POA may be involved in the regulation of a range of functionally different sympathetic outflow systems in the IML. In the rat, sympathetic control of tail skin blood flow is important for the regulation of heat loss from the body, and during fever, reduction in heat loss partly contributes to the rise in body temperature. An anatomical study with viral tract tracer injections into the wall of the tail artery showed transneuronal labeling of neurons in the RPa and the POA (Smith et al., 1998). An electrophysiological study further reported that glutamate injections close to midline medullary raphe nuclei, including the $\mathrm{RPa}$, activated tail sympathetic nerve activity (Rathner and McAllen, 1999). These facts suggest the involvement of POArRPa transmission in the sympathetic control of heat-loss reduction during fever. In addition, central $\mathrm{PGE}_{2}$ administration is known to sympathetically increase blood pressure and heart rate (Hoffman et al., 1986); it is possible that POA-rRPa transmission further mediates these cardiovascular responses to $\mathrm{PGE}_{2}$.

Our neural tract tracing studies have shown that most of the EP3 receptor-expressing POA neurons that likely control the $\mathrm{rRPa}$ are distributed in the MPO, especially in its lateral part. A previous study in which $\mathrm{PGE}_{2}$ was microinjected into various POA subregions proposed that the ventromedial preoptic area (VMPO) is a candidate region for the febrile action of $\mathrm{PGE}_{2}$ (Scammell et al., 1996). However, microinjections into the MPO or MnPO also effectively induced fever in the same report (Scammell et al., 1996). Furthermore, a viral tract tracing study suggested that sympathetic-related POA neurons were distributed in the MPO and MnPO but scarcely in the VMPO (Westerhaus and Loewy, 1999). Therefore, the lateral part of the MPO might be the major site of action of $\mathrm{PGE}_{2}$ for fever induction rather than the VMPO. In addition, the EP3 receptor-expressing POA neuronal group may mediate induction of other inflammatory acutephase responses through as yet unidentified projections from these neurons, because $\mathrm{PGE}_{2}$ produced during infections is thought to induce various symptoms such as anorexia, headache, confusion, and malaise in addition to fever (Elmquist et al., 1997). This gives us an idea that the EP3 receptor-expressing POA neuronal group functions as an important "gate" through which immune signals are transmitted to diverse regions of the CNS and probably constitutes important neural pathways involved in the host defense against diseases, of which fever is an important component.

\section{REFERENCES}

Amir S, Schiavetto A (1990) Injection of prostaglandin $E_{2}$ into the anterior hypothalamic preoptic area activates brown adipose tissue thermogenesis in the rat. Brain Res 528:138-142.
Atkins E (1960) Pathogenesis of fever. Physiol Rev 40:580-646.

Atkins E, Bodel P (1972) Fever. N Engl J Med 286:27-34.

Bamshad M, Song CK, Bartness TJ (1999) CNS origins of the sympathetic nervous system outflow to brown adipose tissue. Am J Physiol 276:R1569-R1578.

Bowker RM, Westlund KN, Coulter JD (1981) Origins of serotonergic projections to the spinal cord in rat: an immunocytochemicalretrograde transport study. Brain Res 226:187-199.

Cao C, Matsumura K, Ozaki M, Watanabe Y (1999) Lipopolysaccharide injected into the cerebral ventricle evokes fever through induction of cyclooxygenase-2 in brain endothelial cells. J Neurosci 19:716-725.

Elmquist JK, Scammell TE, Saper CB (1997) Mechanisms of CNS response to systemic immune challenge: the febrile response. Trends Neurosci 20:565-570.

Esclapez M, Tillakaratne NJK, Tobin AJ, Houser CR (1993) Comparative localization of mRNAs encoding two forms of glutamic acid decarboxylase with nonradioactive in situ hybridization methods. J Comp Neurol 331:339-362.

Feldberg W, Saxena PN (1971) Further studies on prostaglandin $\mathrm{E}_{1}$ fever in cats. J Physiol (Lond) 219:739-745.

Furuta T, Tomioka R, Taki K, Nakamura K, Tamamaki N, Kaneko T (2001) In vivo transduction of central neurons using recombinant Sindbis virus: Golgi-like labeling of dendrites and axons with membranetargeted fluorescent proteins. J Histochem Cytochem 49:1497-1507.

Hoffman WE, Albrecht RF, Miletich DJ (1986) Effect of sympathetic blockade on central prostaglandin $\mathrm{E}_{2}$-induced hyperthermia. Brain Res 367:73-76.

Horn T, Wilkinson MF, Landgraf R, Pittman QJ (1994) Reduced febrile responses to pyrogens after lesions of the hypothalamic paraventricular nucleus. Am J Physiol 267:R323-R328.

Imai-Matsumura K, Matsumura K, Nakayama T (1984) Involvement of ventromedial hypothalamus in brown adipose tissue thermogenesis induced by preoptic cooling in rats. Jpn J Physiol 34:939-943.

Kluger MJ (1991) Fever: role of pyrogens and cryogens. Physiol Rev 71:93-127.

Loewy AD (1981) Raphe pallidus and raphe obscurus projections to the intermediolateral cell column in the rat. Brain Res 222:129-133.

Matsumura K, Cao C, Ozaki M, Morii H, Nakadate K, Watanabe Y (1998) Brain endothelial cells express cyclooxygenase-2 during lipopolysaccharide-induced fever: light and electron microscopic immunocytochemical studies. J Neurosci 18:6279-6289.

Moriyoshi K, Richards LJ, Akazawa C, O'Leary DDM, Nakanishi S (1996) Labeling neural cells using adenoviral gene transfer of membrane-targeted GFP. Neuron 16:255-260.

Morrison SF, Sved AF, Passerin AM (1999) GABA-mediated inhibition of raphe pallidus neurons regulates sympathetic outflow to brown adipose tissue. Am J Physiol 276:R290-R297.

Murphy AZ, Rizvi TA, Ennis M, Shipley MT (1999) The organization of preoptic-medullary circuits in the male rat: evidence for interconnectivity of neural structures involved in reproductive behavior, antinociception and cardiovascular regulation. Neuroscience 91: 1103-1116.

Nakamura K, Kaneko T, Yamashita Y, Hasegawa H, Katoh H, Ichikawa A, Negishi M (1999) Immunocytochemical localization of prostaglandin EP3 receptor in the rat hypothalamus. Neurosci Lett 260:117-120.

Nakamura K, Kaneko T, Yamashita Y, Hasegawa H, Katoh H, Negishi M (2000) Immunohistochemical localization of prostaglandin EP3 receptor in the rat nervous system. J Comp Neurol 421:543-569.

Nakamura K, Li Y-Q, Kaneko T, Katoh H, Negishi M (2001) Prostaglandin EP3 receptor protein in serotonin and catecholamine cell groups: a double immunofluorescence study in the rat brain. Neuroscience 103:763-775.

Negishi M, Sugimoto Y, Ichikawa A (1995) Molecular mechanisms of diverse actions of prostanoid receptors. Biochim Biophys Acta 1259:109-120.

Niijima A, Rohner-Jeanrenaud F, Jeanrenaud B (1984) Role of ventromedial hypothalamus on sympathetic efferents of brown adipose tissue. Am J Physiol 247:R650-R654.

Paxinos G, Watson C (1998) The rat brain in stereotaxic coordinates, Ed 4. San Diego: Academic.

Perkins MN, Rothwell NJ, Stock MJ, Stone TW (1981) Activation of brown adipose tissue thermogenesis by the ventromedial hypothalamus. Nature 289:401-402.

Rathner JA, McAllen RM (1999) Differential control of sympathetic drive to the rat tail artery and kidney by medullary premotor cell groups. Brain Res 834:196-199.

Rothwell NJ (1992) Eicosanoids, thermogenesis and thermoregulation. Prostaglandins Leukot Essent Fatty Acids 46:1-7.

Sagar SM, Sharp FR, Curran T (1988) Expression of c-fos protein in brain: metabolic mapping at the cellular level. Science 240:1328-1331.

Scammell TE, Elmquist JK, Griffin JD, Saper CB (1996) Ventromedial preoptic prostaglandin $\mathrm{E}_{2}$ activates fever-producing autonomic pathways. J Neurosci 16:6246-6254.

Skagerberg G, Björklund A (1985) Topographic principles in the spinal 
projections of serotonergic and non-serotonergic brainstem neurons in the rat. Neuroscience 15:445-480.

Smith JE, Jansen ASP, Gilbey MP, Loewy AD (1998) CNS cell groups projecting to sympathetic outflow of tail artery: neural circuits involved in heat loss in the rat. Brain Res 786:153-164.

Stitt JT (1973) Prostaglandin $\mathrm{E}_{1}$ fever induced in rabbits. J Physiol (Lond) 232:163-179.

Swanson LW (1992) Brain maps: structure of the rat brain. Amsterdam: Elsevier.

Tamamaki N, Nakamura K, Furuta T, Asamoto K, Kaneko T (2000) Neurons in Golgi-stain-like images revealed by GFP-adenovirus infection in vivo. Neurosci Res 38:231-236.

Uno T, Shibata M (2001) Role of inferior olive and thoracic IML neurons in nonshivering thermogenesis in rats. Am J Physiol 280:R536R546.
Ushikubi F, Segi E, Sugimoto Y, Murata T, Matsuoka T, Kobayashi T, Hizaki H, Tuboi K, Katsuyama M, Ichikawa A, Tanaka T, Yoshida N, Narumiya S (1998) Impaired febrile response in mice lacking the prostaglandin E receptor subtype EP3. Nature 395:281-284.

Westerhaus MJ, Loewy AD (1999) Sympathetic-related neurons in the preoptic region of the rat identified by viral transneuronal labeling. J Comp Neurol 414:361-378.

Williams JW, Rudy TA, Yaksh TL, Viswanathan CT (1977) An extensive exploration of the rat brain for sites mediating prostaglandininduced hyperthermia. Brain Res 120:251-262.

Yamagata K, Matsumura K, Inoue W, Shiraki T, Suzuki K, Yasuda S, Sugiura H, Cao C, Watanabe Y, Kobayashi S (2001) Coexpression of microsomal-type prostaglandin E synthase with cyclooxygenase- 2 in brain endothelial cells of rats during endotoxin-induced fever. J Neurosci 21:2669-2677. 